\title{
A novel emaravirus comprising five RNA segments is associated with ringspot disease in oak
}

\author{
Marius Rehanek $^{1}$ - Susanne von Bargen ${ }^{1}\left[\right.$ ] Martina Bandte ${ }^{1} \cdot$ David G. Karlin $^{2} \cdot$ Carmen Büttner $^{1}$
}

Received: 8 September 2020 / Accepted: 25 November 2020 / Published online: 18 January 2021

(c) The Author(s) 2021

\begin{abstract}
We report the complete nucleotide sequence of the genome of a novel virus in ringspot-diseased common oak (Quercus robur $\mathrm{L}$.). The newly identified pathogen is associated with leaf symptoms such as mottle, chlorotic spots and ringspots on diseased trees. High-throughput sequencing (HTS, Illumina RNASeq) was used to explore the virome of a ringspot-diseased oak that had chlorotic ringspots of suspected viral origin on leaves for several years. Bioinformatic analysis of the HTS dataset followed by RT-PCR enabled us to determine complete sequences of four RNA genome segments of a novel virus. These sequences showed high similarity to members of the genus Emaravirus, which includes segmented negative-stranded RNA viruses of economic importance. To verify the ends of each RNA, we conducted rapid amplification of cDNA ends (RACE). We identified an additional genome segment (RNA 5) by RT-PCR using a genus-specific primer (PDAP213) to the conserved 3' and 5'termini in order to amplify full-length genome segments. RNA 5 encodes a 21-kDa protein that is homologous to the silencing suppressor P8 of High Plains wheat mosaic virus. The five viral RNAs were consistently detected by RT-PCR in ringspot-diseased oaks in Germany, Sweden, and Norway. We conclude that the virus represents a new member of the genus Emaravirus affecting oaks in Germany and in Scandinavia, and we propose the name "common oak ringspot-associated emaravirus" (CORaV).
\end{abstract}

In Germany, chlorotic ringspots, mottling and chlorotic spots have been observed for decades on leaves of common oak (Quercus robur L.) [1]. Mechanical transmission of the symptoms to healthy oak seedlings failed, although graft transmissibility had been demonstrated earlier [2]. A viral cause for the observed symptoms was thought likely, and this hypothesis was supported by electron microscopy images of virus-like particles with spherical morphology [3]. Attempts to determine the causal agent by serological

Handling Editor: Ioannis E. Tzanetakis.

Supplementary Information The online version contains supplementary material available at https://doi.org/10.1007/s0070 5-021-04955-w.

Susanne von Bargen

susanne.von.bargen@agrar.hu-berlin.de

1 Division Phytomedicine, Albrecht Daniel Thaer-Institute of Agricultural and Horticultural Sciences, HumboldtUniversität zu Berlin, Lentzeallee 55/57, 14195 Berlin, Germany

2 Independent Scholar, Marseille, France testing and molecular approaches excluded known viruses affecting Quercus [4].

Here, we report the complete genome sequence of a novel emaravirus based on its initial identification in a ringspot-diseased common oak tree in Kreuztal, Germany, using high-throughput sequencing (HTS, Illumina, HiSeq), first employing a random sequencing approach, followed by an emaravirus-enrichment strategy for library preparation [5]. In the HTS datasets, we identified sequence contigs relating to four genome segments of a putative novel emaravirus by using the Basic Local Alignment Tool X (BLASTx) against the NRPROT database, and we established diagnostic RT-PCR assays targeting RNA 2-RNA 4 of the novel virus [5]. The genus Emaravirus is part of the family Fimoviridae (order Bunyavirales) and includes plant viruses with a segmented, negative-stranded RNA genome. At least four genome segments are present in all members described to date [6]. We obtained the complete sequences of RNA 1 and RNA 2 of the novel virus by RT-PCR using species-specific primer pairs (see Supplemental Table S1) derived from HTS-based sequences. To amplify full-length genome segments of the putative RNA $3(1.3 \mathrm{~kb})$ and RNA $4(1.4 \mathrm{~kb})$ and to check for further genomic components, 
we performed RT-PCR using the terminal primer PDAP213 and velocity polymerase (Bioline) as described for other emaraviruses [7, 8]. PDAP213-primed RT-PCR amplified a putative fifth genome component, RNA 5, with a length of approximately $1 \mathrm{~kb}$, from samples from three locations in Germany and Sweden. We cloned the full-length PCR products and sequenced two individual clones of RNA 3, four of RNA 4, and four of RNA 5 as described elsewhere [8]. BLASTx analysis (NCBI) confirmed that the cloned PCR products represent complete genome segments of the novel virus. Deduced aa sequences of the novel virus identified in oak showed $21-38 \%$ (RNA 3), 18-58\% (RNA 4), and $18-41 \%$ (RNA 5) sequence identity to the corresponding protein sequences encoded by High Plains wheat mosaic virus (HPWMoV), raspberry leaf blotch virus (RLBV), ti ringspot-associated virus (TiRSaV) [9], jujube yellow mottleassociated virus (JYMaV) [10], and blue palo verde broom virus (PVBV) [11]. We determined the sequence termini of each RNA segment by rapid amplification of cDNA ends (RACE) as described [8], using specific primers complementary to the genomic and antisense strand, respectively, of each RNA (Table S1).

The putative functions of proteins encoded by RNA 1 to RNA 4 of this virus were deduced based on the presence of conserved domains related to those of other emaraviruses. The RNA-dependent RNA polymerase (RdRP) is encoded by RNA 1 (2317 aa, $271.7 \mathrm{kDa}$ ), while RNA 2 encodes the glycoprotein precursor (GPP, $651 \mathrm{aa}, 74.2 \mathrm{kDa}$ ). The viral nucleocapsid protein (NC, $291 \mathrm{aa}, 32.9 \mathrm{kDa}$ ) is encoded by RNA 3, and RNA 4 encodes the movement protein (MP, 365 aa, $41.7 \mathrm{kDa}$ ) (Fig. 1). We aligned amino acid sequences of the viral RdRP, GPP, NC, and MP of the novel virus identified in ringspot-diseased oak with sequences of homologous proteins of emaraviruses to establish their phylogeny. The novel virus clustered consistently with a group of emaraviruses comprising HPWMoV, RLBV, TiRSaV, JYMaV, and PVBV, regardless of the protein considered (Fig 2A. phylogenetic trees for GPP and MP not shown). Phylogenetic analysis and species demarcation criteria for emaraviruses (sequence divergence of over $25 \%$ for proteins encoded by viral RNA 1, RNA 2 and RNA 3 [12]) indicate that the virus represents a distinct species of the genus emaravirus. This conclusion is reinforced by the structure of the genome, which has (i) at least five RNA segments, each containing one ORF, (ii) conserved 13-nt sequences at the 5' and 3' termini of each RNA, and (iii) partial complementarity at the terminal ends of each genome segment. Based on the observed ringspot symptoms on leaves, we propose the name "common oak ringspot-associated emaravirus" $(\mathrm{CORaV})$ for the novel virus.

RNA 5 (1030 nt) of CORaV contains one major open reading frame, coding for a protein of $179 \mathrm{aa}(\mathrm{P} 5,21.1 \mathrm{kDa})$. We identified sequence similarity to the putative silencing suppressor P8 of HPWMoV [13] and to proteins encoded by other emaraviruses as described elsewhere [8], with sequence similarities ranging from 18\% (RLBV P7) to $41 \%$ (TiRSaV P5). CORaV P5 is predicted to be mostly $\alpha$-helical, and the alignment of its $\mathrm{N}$-terminal moiety (Fig. 2B), which is the region best conserved across all homologs (aa 17-104 in CORaV P5), shows that one aspartate is strictly conserved in all species (D75 in CORaV P5), while three positions are semi-conserved, containing the basic amino acid arginine (R103) or lysine (K65 and K85). However, the function of $\mathrm{P} 5$ remains to be elucidated.

We correlated the detection of all five viral RNAs to the occurrence of the ringspot disease of oaks. Leaf material from healthy and ringspot-diseased oaks at over 25 locations in Germany, Sweden, and Norway was sampled from landscape, nursery-grown, and urban trees. In 191 out of 198 Q . robur samples, we confirmed the presence of viral RNAs by RT-PCR applying species-specific primers (Table S1) targeting all five genome segments. We observed chlorotic ringspots and spots on diseased trees as the most abundant symptoms (Supplemental Fig. S1, left side), and

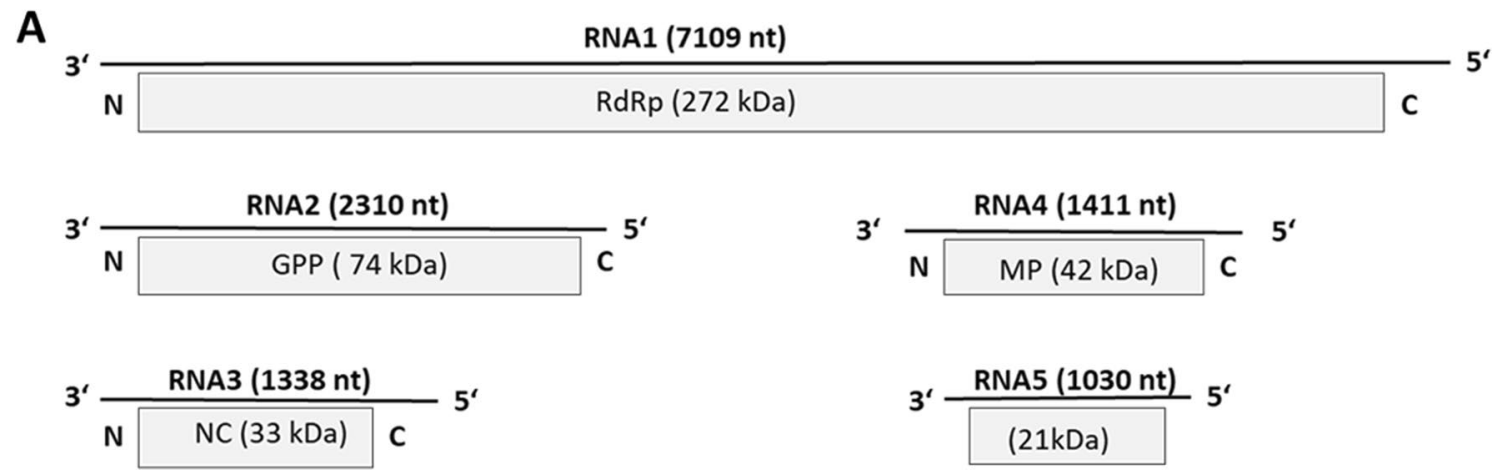

Fig. 1 Genome organization of common oak ringspot-associated virus $(\mathrm{CORaV})$. Genome segments are displayed as mRNA, with grey boxes representing the protein encoding region (ORF) for each

RNA. The protein encoded by each RNA and its predicted molecular mass are given. RdRP, RNA-dependent RNA polymerase; GPP, glycoprotein precursor; $\mathrm{NC}$, nucleocapsid; MP, movement protein 


\section{a}

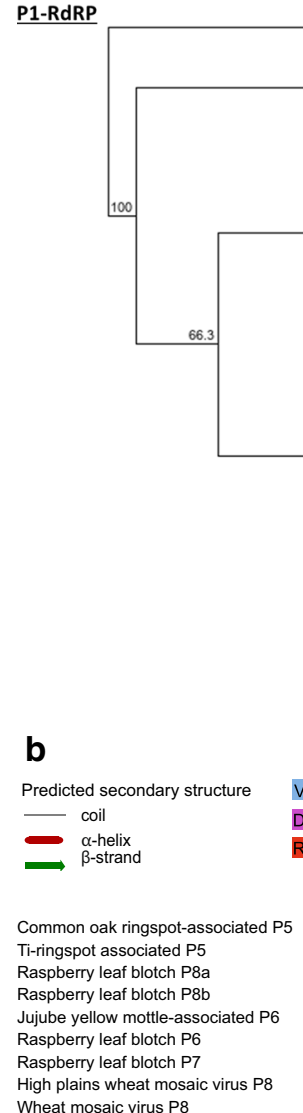

(NP_049362)

(LC496090)

(MN385573)

- CjeV2 (MN385577)

99.8 HPWMOV (AIK23031)

L PVBV (AWH90163)

100 - JYMaV (QDM38999)

$100-$ RLBV (CBZ42024)

- TiRSaV (QAB47307)

- EMARaV (AAS73287)

100 - AcCRaV (ALX00127)

- RYRSaV (AE095760)

-1 (CUR49050)

(AOX45473)

(CCV01186)

(QEE82886)

$(\mathrm{aBH} 2679)$

(ADZ54688)

(CAA0079389)

(QAR18002)

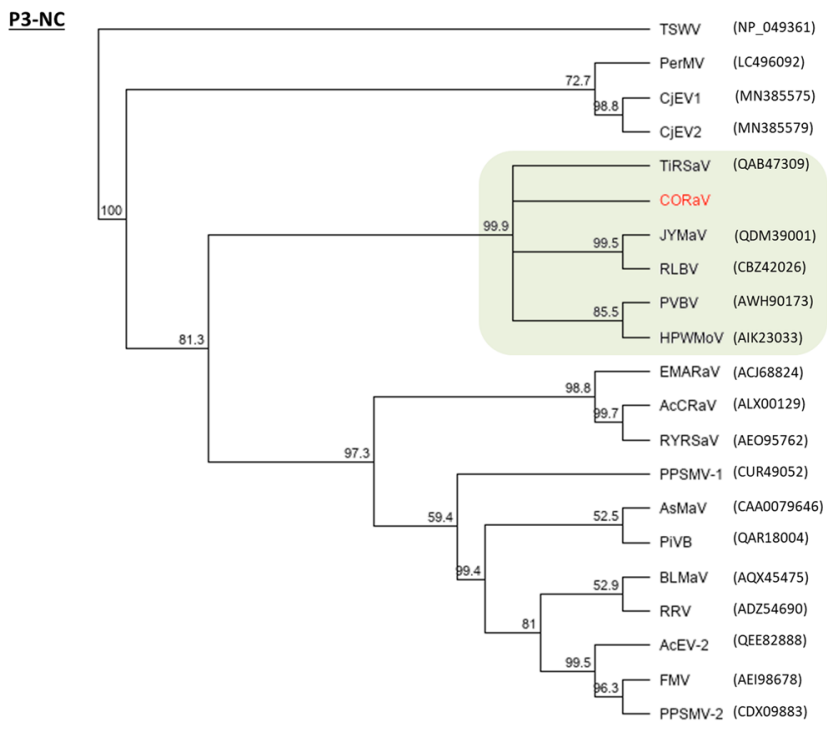

Fig. 2 (A) Phylogenetic placement of common oak ringspot-associated virus (CORaV). We used MUSCLE to align amino acid sequences of the CORaV RdRP and NC with the corresponding sequences of other emaraviruses, including the assigned viruses actinia chlorotic ringspot-associated emaravirus (AcCRaV), blackberry leaf mottle-associated emaravirus (BLMaV), European mountain ash ringspot-associated emaravirus (EMARaV), fig mosaic emaravirus (FMV), High Plains wheat mosaic emaravirus (HPWMoV), pigeonpea sterility mosaic emaraviruses 1 and 2 (PPSMV-1 and PPSMV-2), pistacia emaravirus B (PiVB), raspberry leaf blotch emaravirus (RLBV), rose rosette emaravirus (RRV), and redbud yellow ringspot-associated emaravirus (RYRSaV) as well as the unassigned viruses actinidia virus 2 (AcEV-2), aspen mosaic-associated virus (AsMaV), Camellia japonica associated virus 1 and 2 (CjEV1 and $\mathrm{CjEV} 2$ ), jujube yellow mottle-associated virus (JYMaV), blue

mottle was found only in a few samples. However, in seven trees displaying ringspot symptoms, we did not detect any of the tested $\mathrm{CORaV}$ genome segments. In leaf material collected from trees without any symptoms $(n=28)$, no viral genome segment could be detected. We obtained the same results for leaf samples from 25 trees that had never shown chlorotic ringspots but had either a regular chlorotic pattern or partial chlorosis of leaves (Supplemental Fig. S1, right side). The latter symptoms were therefore considered atypi$\mathrm{cal}$ of $\mathrm{CORaV}$ and not associated with the ringspot disease. We consider it likely that $\mathrm{CORaV}$ contains five genome palo verde broom virus (PVBV), perilla mosaic virus (PerMV), and ti ringspot-associated virus (TiRSaV)). Phylogenetic trees were built using the neighbor-joining method in Geneious prime 2019.1.1 software. Accession numbers are indicated. Numbers on branches represent statistical support based on bootstrap analysis (1000 replicates). $\mathrm{CORaV}$ (red) and other emaraviruses that clustered into the same group are indicated by coloured boxes. Tomato spotted wilt virus (TSWV, genus Orthotospovirus) was used as an outgroup. (B) Alignment of a partial CORaV P5 sequence and its homologs. The accession numbers of the sequences used are as follows: QAB47311.1 (TiRSaV P5), AIK23039.1 (HPWMoV P8), AML03198.1 (HPWMoV P8), YP_009237280.1 (RLBV P8a), AKU41979.1 (RLBV P8b), QDM39004.1 (JYMaV P6), YP_009237279.1 (RLBV P7), AKU41976.1 (RLBV P6).

segments and is associated with the ringspot disease in common oak. Since virus infections represent a significant predisposition for other diseases and stress, further studies are needed to fully understand the biology and epidemiology of $\mathrm{CORaV}$ as well as its impact on the health status of trees, a prerequisite for effective disease management.

Acknowledgements The authors would like to thank Renate Junge and Andrea Klinke for skilled technical assistance. This work was essentially financed by FAZIT-STIFTUNG Gemeinnützige Verlagsgesellschaft $\mathrm{mbH}$. Partial funding by the German Research Foundation (DFG, project number Bu890/27-1) and the European Cooperation in 
Science and Technology (COST action FA1407 "DIVAS") is kindly acknowledged.

Funding Open Access funding enabled and organized by Projekt DEAL. This study was funded by FAZIT-STIFTUNG Gemeinnützige Verlagsgesellschaft mbH (personal grant to Marius Rehanek, no Grant number provided), the German Research Foundation (Grant number Bu890/27-1), and the European Cooperation in Science and Technology (Grant number FA1407).

\section{Compliance with ethical standards}

Conflict of interest Marius Rehanek declares that he has no conflict of interest. Susanne von Bargen declares that she has no conflict of interest. Martina Bandte declares that she has no conflict of interest. David G. Karlin declares that he has no conflict of interest. Carmen Büttner declares that she has no conflict of interest.

Ethical approval This article does not contain any studies with human participants or animals performed by any of the authors.

Open Access This article is licensed under a Creative Commons Attribution 4.0 International License, which permits use, sharing, adaptation, distribution and reproduction in any medium or format, as long as you give appropriate credit to the original author(s) and the source, provide a link to the Creative Commons licence, and indicate if changes were made. The images or other third party material in this article are included in the article's Creative Commons licence, unless indicated otherwise in a credit line to the material. If material is not included in the article's Creative Commons licence and your intended use is not permitted by statutory regulation or exceeds the permitted use, you will need to obtain permission directly from the copyright holder. To view a copy of this licence, visit http://creativecommons.org/licenses/by/4.0/.

\section{References}

1. Büttner C, von Bargen S, Bandte M, Mühlbach HP (2013) Forest diseases caused by viruses. Infect For Dis. 50-75S (CAB International)

2. Büttner C, Führling M (1996) Studies on virus infection of diseased Quercus robur (L) from forest stands in northern Germany. Ann Sci For 53:383-388
3. Nienhaus F (1985) Infectious diseases in forest trees caused by viruses, mycoplasma-like organisms and primitive bacteria. Experentia 41:597-603

4. Steinmöller S, Bandte M, Büttner C (2004) Untersuchungen zum Erreger der Ringfleckigkeit an Stieleichen (Quercus robur). Gesunde Pflanzen 56:11-16

5. Bandte M, Rehanek M, Leder B, von Bargen S, Büttner C (2020) Identification of an Emaravirus in a Common Oak (Quercus robur L.) Conservation Seed Orchard in Germany: Implications for Oak Health. Forests 11:1174-1189

6. Mielke-Ehret N, Mühlbach HP (2012) Emaravirus: a novel genus of multipartite, negative strand RNA plant viruses. Viruses 4:1515-1536

7. Di Bello PL, Ho T, Tzanetakis IE (2015) The evolution of emaraviruses is becoming more complex: seven segments identified in the causal agent of Rose rosette disease. Virus Res 210:241-244

8. von Bargen S, Al Kubrusli R, Gaskin T et al (2020) Characterisation of a novel Emaravirus identified in mosaic-diseased Eurasian aspen (Populus tremula). Ann Appl Biol. 176:2010-2222

9. Olmedo-Velarde A, Park AC, Sugano J, Uchida JY, Kawate M, Borth WB, Hu JS, Melzer MJ (2019) Characterization of Ti ringspot-associated virus, a novel emaravirus associated with an emerging ringspot disease of Cordyline fruticosa. Plant Dis. 103(9):2345-2352

10. Yang C, Zhang S, Han T, Fu J, Di Serio F, Cao M (2019) Identification and characterization of a novel emaravirus associated with jujube (Ziziphus jujuba Mill.) yellow mottle disease. Front Microbiol. 10:1417

11. Ilyas M, Avelar S, Schuch UK, Brown JK (2018) First report of an emaravirus associated with witches' broom disease and Eriophyid mite infestations of the blue Palo Verde tree in Arizona. APS 102(9):1863-1863

12. Elbeaino T, Digiaro M, Mielke-Ehret N, Mühlbach H, Martelli GP, ICTV Report Consortium (2018) ICTV virus taxonomy profile: Fimoviridae. J General Virol 99:1478-1479

13. Gupta AK, Hein GL, Graybosch RA, Tatineni S (2018) Octapartite negative-sense RNA genome of High Plains wheat mosaic virus encodes two suppressors of RNA silencing. Virology 518:152-162

Publisher's Note Springer Nature remains neutral with regard to jurisdictional claims in published maps and institutional affiliations. 